\title{
Comparison of Antifungal Activity of Extracts of Ten Plant Species and Griseofulvin Against Human Pathogenic Dermatophytes
}

\author{
Alireza Massiha," ${ }^{1, *}$ and Panah Zolfaghar Muradov ${ }^{2}$ \\ ${ }^{1}$ Department of Biotechnology, Islamic Azad University, Lahijan Branch, Lahijan, IR Iran \\ ${ }^{2}$ Department of Microbiology, Institute of Microbiology, Azerbaijan National Academy of Sciences, Baku, Azerbaijan \\ ${ }^{*}$ Corresponding author: Alireza Massiha, Department of Biotechnology, Islamic Azad University, Lahijan Branch, Lahijan, IR Iran. E-mail: amirmassiha@yahoo.com
}

Received 2014 June 9; Accepted 2014 October 1.

\begin{abstract}
Background: This study was conducted to measure the antifungal activity of the extracts of 10 plant species used in traditional Iranian medicine against human pathogenic dermatophytes.

Materials and Methods: In this experimental study, the leaves of these plants (Calendula officinalis, Acacia arabica, Altheae officinalis, Ginkgo biloba, Juglans regia, Osimum basilicum, Solanum nigrum, Hypericum perforatum, Urtica dioica, and Anagalis arvensis) were taken and extractions were made in methanol and were tested against Microsporum canis, Microsporum gypseum, Trichophyton mentagrophytes, Trichophyton rubrum, Trichophyton schoenleinii, and Epidermophyton floccosum. The minimum inhibitory concentration (MIC) was determined using broth macrodilution method. The effects of plants extracts were compared with those of griseofulvin.

Results: Plants under review showed antifungal activity against all the dermatophytes tested with MIC values ranging from 0.001 to $0.016 \mathrm{mg} / \mathrm{mL}$ using inhibitory zone estimation, 0.3 to $12.8 \mathrm{mg} / \mathrm{mL}$ using agar dilution method and 0.2 to $12.5 \mathrm{mg} / \mathrm{mL}$ using broth dilution method. The minimum fungicidal concentration (MFC) of the extracts ranged from 0.8 to $15.62 \mathrm{mg} / \mathrm{mL}$.

Conclusions: The results obtained suggested that $H$. perforatum, A. arvensis, and A. arabica have anti-dermatophyte activity.
\end{abstract}

Keywords: Antifungal Activity, Biochemical Components, Methanol Extract, Dermatophytes, Minimum Inhibitory Concentration

\section{Background}

Medicinal plants have been used for centuries as remedies for human diseases. They constitute an effective source of both traditional and modern medicine. The acceptance of traditional medicine as an alternative form of health care hassled researchers to further investigate antimicrobial activity of medicinal plants. Some countries in Africa, Asia, and Latin America use traditional medicine to help meet some of their primary health care needs [1]. The use of plant compounds to treat infections is an age-old practice in large parts of the world, especially in developing countries, where there is dependence on traditional medicine for a variety of diseases $[2,3]$. Interest in plants with antimicrobial properties has revived as a result of current problems associated with the use of antibiotics [4,5]. Dermatophytes are the fungal pathogens of humans and animals infecting the keratinized tissues e.g. skin, nails, and hairs, since they are most likely found in hot humid areas [6]. These fungi can easily digest the keratinized tissue by releasing sulphite, exoprotease, and endoprotease [7]. Sulphite being a reducing agent broke the disulphide bonds of keratin protein and made them more vulnerable to fungal proteases enzymes. The diseases caused by dermatophytes are also known as dermatoses and their prevalence depend upon the activity of peoples [8]. Human infections, particularly those involving the skin and mucosal surface constitute a serious problem, especially in tropical and subtropical developing countries; dermatophytes and Candida spp. being the most frequent pathogen. Herbal medicines have been important sources of products for the developing countries in treating common infections including fungal diseases. Some studies have demonstrated that the plant extract has been used traditionally to treat a number of infectious diseases caused by bacteria and fungi [9-13].

Many researchers, particularly the ones from countries with a rich biodiversity, have contributed to the detection of new antifungal compounds in medicinal plants. Screening used in vitro evaluation is a useful tool for the discovery of new potential antifungal agents from natural products such as essential oils and extracts derived from plants.

\section{Objectives}

The aim of this work was an evaluation in vitro the potential antifungal activity of native plants against human pathogenic dermatophytes in order to verify possible inhibition activity. Moreover, the smallest concentration capable of inhibiting or preventing growth was determined among the species and extracts that demonstrated inhibitory properties. In order to determine these activities, a comprehensive screening study was carried out

Copyright (C) 2015, Zahedan University of Medical Sciences. This is an open-access article distributed under the terms of the Creative Commons Attribution-NonCommercial 4.0 International License (http://creativecommons.org/licenses/by-nc/4.0/) which permits copy and redistribute the material just in noncommercial usages, provided the original work is properly cited. 
Massiha A et al.

for 10 plant species collected from north of Iran (Guilan).

\section{Materials and Methods}

\subsection{Plant Collection and Identification}

In this experimental study, the leaves of the different plants involve Calendula officinalis, Acacia arabica, Altheae officinalis, Ginkgo biloba, Juglans regia, Osimum basilicum, Solanum nigrum, Hypericum perforatum, Urtica dioica, and Anagalis arvensis, were collected from north of Iran. These plants were identified by the plant taxonomy laboratory, Department of Botany, Islamic Azad University of Iran, Lahijan Branch. Fresh plant material were washed under running tap water, air dried, and then homogenized to fine powder and stored in airtight bottles.

This study comprised of samples received from all the patients suspected of fungal infections over a period of one year (March 2009 to August 2009) in the Microbiology Laboratory which is attached to Razi's general hospital in northern Iran (Guilan Province).

\subsection{Preparation of Extracts}

An extraction was carried out by Soxhlet procedure as described by Horowitz (1984). Thirty grams of the dried plant leaf was extracted with $300 \mathrm{~mL}$ of methanol (BDH). The process was repeated using $500 \mathrm{~mL}$ hexane $(\mathrm{BDH})$ as solvent. The extracts were recovered from the solvent using rotavapour apparatus and stored in a freezer $\left(-20^{\circ} \mathrm{C}\right)$ for subsequent antifungal activities. Fresh leaf $(20 \mathrm{~g})$ was blended with $10 \mathrm{~mL}$ of water in a Moulinex blender for 5 minutes and the suspension filtered through muslin cloth. A clear filtrate obtained by further filtration of the suspension through grade No. 1 filter paper, Whatman (manufactured by Whatman, U.K.) and sterilized at $121^{\circ} \mathrm{C}$ for 15 minutes was used to impregnate discs (6 mm) [14]. In this study, the phytochemical combinations, including alkaloids, carbohydrates/glycosides, flavonoids, oils, phenolic compounds, proteins/aminoacids, proteins/aminoacids, saponin, steroids, tannin, terpenoids, and reducing suger are analyzed.

\subsection{Fungi Isolates}

The test species and isolates used for this investigation were: Microsporum canis, Microsporum gypseum, Trichophyton mentagrophytes, Trichophyton rubrum, Trichophyton schoenleinii, and Epidermophyton floccosum. Identification of isolates obtained was performed according to standard methods [15].

\subsection{Antifungal Assay of Methanolic Extracts}

A qualitative antifungal screening was carried out using the agar well diffusion assay. Twenty milliliter of sterilized Sabouraud dextrose agar medium was poured into a $15 \mathrm{~cm}$ Petri dish. Twenty microliter of inoculums suspension of each test organism was distributed evenly over the surface. A $6 \mathrm{~mm}$ well was cut in the center of each plate using the wide-end of a sterilized Pasteur pipette. Fifty microliter of serial dilution of metabolic leaf extracts of selected native plants or griseofulvin were placed into the wells. The plates were incubated for 5 days at $30^{\circ} \mathrm{C}$. Results of the qualitative screening were recorded as the average diameter of the inhibition zone surrounding the wells containing the test solution. Results were compared with griseofulvin. The percentage of mycelia inhibition was calculated as follows:

(1)

$$
\text { mycelia inhibition }(\%)=\left[\frac{\mathrm{dc}-\mathrm{dt}}{\mathrm{dc}}\right] \times 100
$$

dc: colony diameter in control, dt: colony diameter in treatment.

Three replicate plates were used for each treatment. The MIC was regarded as the lowest concentration that produced a visible zone of inhibition [16].

\subsection{Minimum Inhibitory Concentration (MIC)}

MIC of extract was determined by broth dilution method. For this purpose, $1 \mathrm{~mL}$ of sterile liquid Sabouraud medium was added to 11 sterile capped tubes. Each $1 \mathrm{~mL}$ methanolic leaf extracts suspension ( $12.8 \mathrm{mg} / \mathrm{mL}$ in medium) was added to tube 1 . The contents were mixed and $1 \mathrm{~mL}$ was transferred to tube 2. This serial dilution was repeated through to tube 9. One milliliter was discarded from tube 9. Fifty microliter of inoculum was added to tubes $1-10$ and the contents were mixed. Medium control (no inoculum and no drug) and inoculum control (no drug) tubes were prepared. The final concentrations of selected native plants extract ranged from 6.4 to $0.025 \mathrm{mg} / \mathrm{mL}$. For griseofulvin, the final concentration ranged from $0.064-0.00025 \mathrm{mg} / \mathrm{mL}$. The tubes were incubated at $30^{\circ} \mathrm{C}$ for 72 hours. The fungal growth in each tube was detected turbid metrically at 530 $\mathrm{nm}$. MIC was defined as the drug concentration at which the turbidity of the medium was the same as the medium control. Ten microliter aliquot of cell suspension from the tube without observed growth of fungi was inoculated on to Sabouraud dextrose agar and minimum fungicidal concentration (MFC) of test compound was determined as the lowest concentration of the agent at which no colonies were seen after 4 days at $30^{\circ} \mathrm{C}[17]$.

\subsection{Statistical Analyses}

The comparison of average zone diameters and the evaluation of extract antimicrobial effects were analyzed by SPSS 11.5 and $t$-test. In this experiment, $P$ value was statistically significant $(\mathrm{P}<0.05)$.

\section{Results}

The obtained results of phytochemical combination of methanol extract showed that glycosides and phenolic compounds compared to oil, amino acids, steroids, flavonoids, reduce sugar, and were in more proportions $(\mathrm{P}=$ 0.045) (Table 1). In this research, the percentage of inhibition (Table 2) was calculated after comparing with griseofulvin (100\% inhibition). The maximum activity was obtained 
Massiha A et al.

from Calendula officinalis which was ranged from $66.6 \%$, followed by Juglans regia the greatest inhibitory effect of griseofulvin was recorded with Trichophyton schoenleinii (37 $\mathrm{mm}$; inhibition zone). Microsporum canis showed the most susceptibility against J. regia, A. arvensis, and Hypericum perforatum methanolic extracts ( $65 \mathrm{~mm}, 60 \mathrm{~mm}$, and $55 \mathrm{~mm}$; inhibition zone). The effects of the crude extract of different plants and standard drug at various concentrations are shown in Table 3. Zone of inhibition assay was performed using inhibitory zone estimating. The MIC values represent the average of 3 independent experiments. In this study, the inhibitory effects of methanolic leaf extracts of native plant were studied against 6 species of pathogenic dermatophytes including M. canis, M. gypseum, T. rubrum, T. schoenleinii,T. mentagrophytes, and E. floccosum.

Inhibitory zone estimating, agar dilution method and broth dilution method were used in this study and the results were compared with each other and griseofulvin. The following tables show the effectiveness of antifungal activity of native plants in northern Iran. The results obtained suggest that $H$. perforatum, A. arvensisand, and A. arabica have anti-dermatophyte activity (Tables 3 - 6).

Table 7 showed MIC of species plant extracts against test fungi. Table 8 showed MFC of species plant extracts against test fungi. It was ranged from $0.001-0.016 \mathrm{mg} / \mathrm{mL}$ for griseofulvin. The MICs for the different plant extracts were ranged from 0.2 to $12.5 \mathrm{mg} / \mathrm{mL}$. The antifungal activities of griseofulvin were determined by using broth microdilution technique, against dermatophytes and the MICs for $T$. schoenleinii, E. floccosum, and T. mentagrophytes were ranged from $0.01-0.32 \mathrm{mg} / \mathrm{mL}$. It can be concluded that, MICs calculated were greater than that obtained for griseofulvin.

\begin{tabular}{|c|c|c|c|c|c|c|c|c|c|c|}
\hline \multirow[t]{2}{*}{ Phytochemical Tests } & \multicolumn{10}{|c|}{ Plants } \\
\hline & $\begin{array}{l}\text { Anagalis } \\
\text { arvensis }\end{array}$ & $\begin{array}{l}\text { Juglans } \\
\text { regia }\end{array}$ & $\begin{array}{l}\text { Ginkgo } \\
\text { biloba }\end{array}$ & $\begin{array}{l}\text { Urtica } \\
\text { dioica }\end{array}$ & $\begin{array}{l}\text { Acacia } \\
\text { arabica }\end{array}$ & $\begin{array}{l}\text { Calendula } \\
\text { officinalis }\end{array}$ & $\begin{array}{l}\text { Osimum } \\
\text { basilicum }\end{array}$ & $\begin{array}{l}\text { Solanum } \\
\text { nigrum }\end{array}$ & $\begin{array}{l}\text { Hypericum } \\
\text { perforatum }\end{array}$ & $\begin{array}{c}\text { Althea } \\
\text { officinalis }\end{array}$ \\
\hline Alkaloids & + & + & + & ++ & + & + & + & ++ & - & - \\
\hline $\begin{array}{l}\text { Carbohydrates/glyco- } \\
\text { sides }\end{array}$ & ++ & + & + & + & + & + & - & + & + & ++ \\
\hline Flavonoids & - & + & ++ & + & - & + & + & - & + & - \\
\hline Oils & - & + & - & - & + & - & + & - & + & ++ \\
\hline Phenolic compounds & + & + & + & + & + & + & + & - & + & ++ \\
\hline Proteins/aminoacids & - & + & - & - & + & + & + & - & + & ++ \\
\hline Saponin & ++ & + & + & - & + & + & + & ++ & - & - \\
\hline Steroids & - & - & + & ++ & + & + & - & + & - & + \\
\hline Tannin & - & ++ & + & + & + & - & + & ++ & + & + \\
\hline Terpenoids & + & + & + & ND & - & + & + & - & + & + \\
\hline Reducing suger & + & + & + & ++ & ND & + & - & - & - & + \\
\hline
\end{tabular}

a - , Absent; +, Present;++, Abundant; ND, not defined.

Table 2. The Percent of Inhibition of the Crude Extract of Different Plants Compared to Griseofulvin (100\% Inhibition) Against Different Dermatophytes

\begin{tabular}{|c|c|c|c|c|c|c|}
\hline \multirow[t]{2}{*}{ Plants } & \multicolumn{6}{|c|}{ Fungi Species } \\
\hline & M.canis & M. gypseum & T. rubrum & T. schoenleinii & T. mentagrophytes & E. floccosum \\
\hline S. nigrum & 29 & 27 & 37 & 35 & 33 & 28 \\
\hline H.perforatum & 55 & 48 & 53 & 40 & 43 & 43 \\
\hline A. officinalis & 10 & 2 & 2 & 2 & 2 & 2 \\
\hline O. basilicum & 30 & 35 & 45 & 33.3 & 37.5 & 42.4 \\
\hline A. arvensis & 60 & 42 & 46 & 55 & 45 & 25 \\
\hline U. dioica & 12 & 10 & 8 & 2 & 7 & 10 \\
\hline G. biloba & 25 & 33.3 & 35 & - & 25 & 26.3 \\
\hline C. officinalis & 37.5 & 37.5 & 66.6 & 50 & 26.3 & 65 \\
\hline A. arabica & 50 & 55 & 60 & 37.5 & 42.4 & 55 \\
\hline J. regia & 65 & 55 & 50 & 60 & 50 & 33.3 \\
\hline Griseofulvin & 100 & 100 & 100 & 100 & 100 & 100 \\
\hline
\end{tabular}

Table 3. Griseofulvin Inhibitory Effects on Selected Fungal Species

\begin{tabular}{|c|c|c|c|c|c|c|c|c|c|}
\hline \multirow[t]{2}{*}{ Dermatophytes } & \multicolumn{9}{|c|}{ Extract Inhibitory Concentrations, mg/mL } \\
\hline & 6.4 & 3.2 & 1.6 & 0.8 & 0.4 & 0.2 & 0.1 & 0.05 & 0.025 \\
\hline M. canis & 14 & 9 & 4 & - & - & - & - & - & - \\
\hline M. gypseum & 16 & 11 & 6 & - & - & - & - & - & - \\
\hline T. rubrum & 17 & 12 & 5 & - & - & - & - & - & - \\
\hline T. schoenleinii & 16 & 11 & 5 & - & - & - & - & - & - \\
\hline T. mentagrophytes & 20 & 13 & 6 & 2 & - & - & - & - & - \\
\hline E.floccosum & 19 & 12 & 5 & - & - & - & - & - & - \\
\hline
\end{tabular}


Massiha A et al.

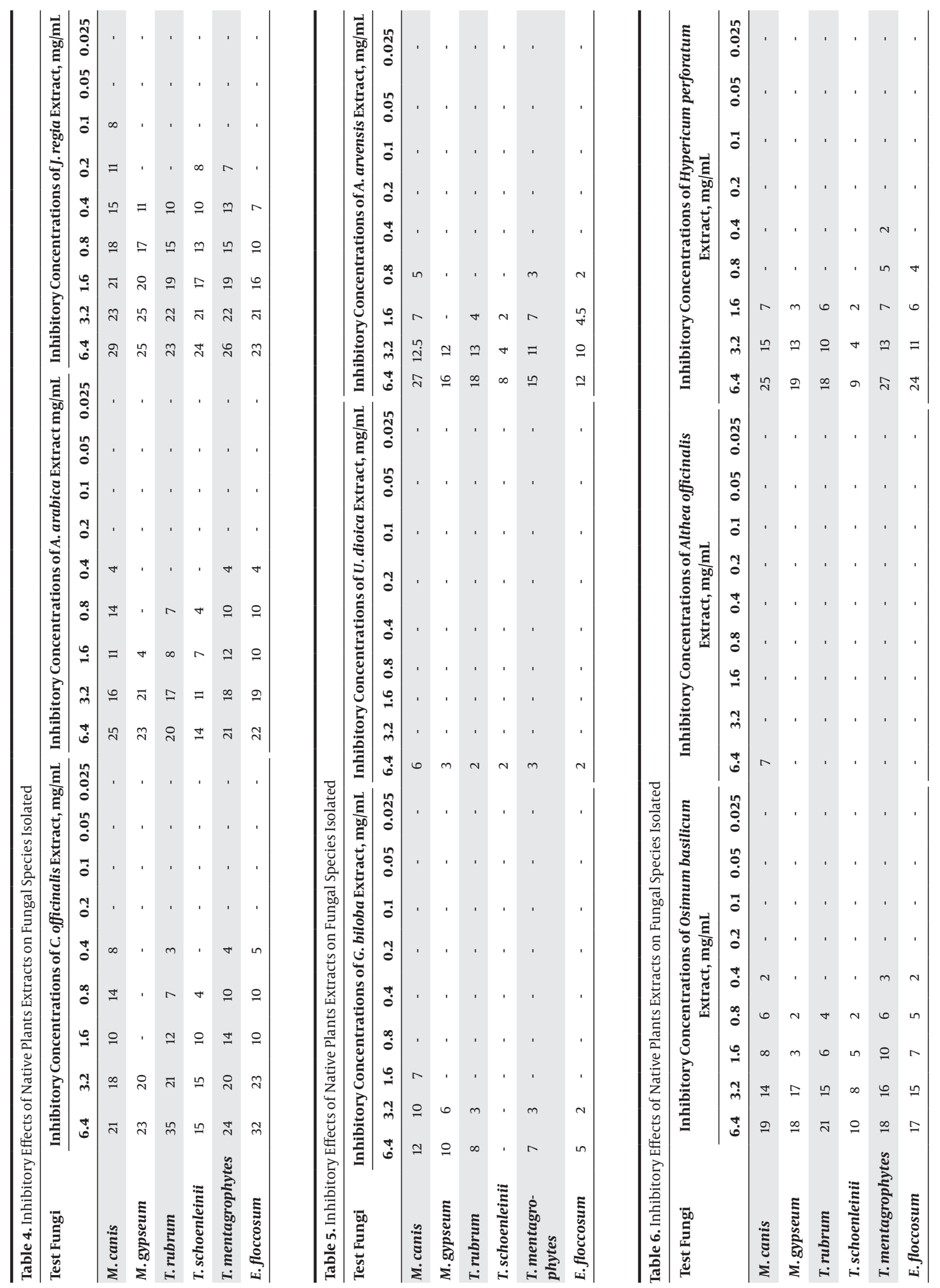


Massiha A et al.

Table 7. MIC Results of Species Plant Extracts Against Test Fungi by Broth Dilution Method

Plant Extract MIC, $\mathrm{mg} / \mathrm{mL}$

\begin{tabular}{|c|c|c|c|c|c|c|c|c|c|c|c|}
\hline Dermatophytes & 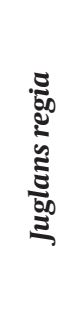 & 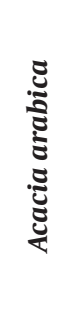 & 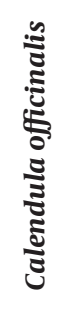 & 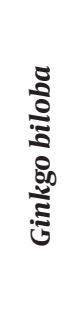 & 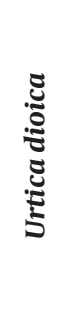 & 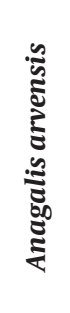 & 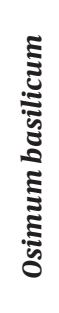 & 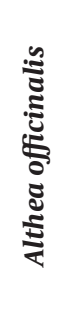 & 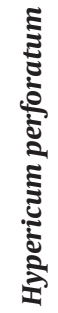 & 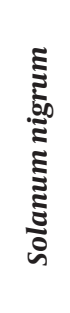 & 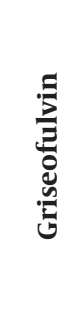 \\
\hline E. floccosum & 0.6 & 0.39 & 0.2 & 7.81 & ND & 0.4 & 1.4 & ND & 0.1 & 6 & 0.002 \\
\hline T. mentagrophytes & 4 & 0.13 & 0.2 & 7.20 & ND & 3.7 & 4.4 & ND & 0.6 & 8.50 & 0.002 \\
\hline T. schoenleinii & 0.86 & 0.17 & 0.4 & 7.20 & ND & 0.4 & 1.2 & ND & 0.1 & 8 & 0.001 \\
\hline T. rubrum & 1.1 & 0.32 & 1.4 & 7.81 & ND & 0.6 & 1.8 & ND & 0.6 & 8.5 & 0.004 \\
\hline M. gypseum & 1.3 & 0.77 & 1.4 & 7.81 & ND & 0.8 & 2.1 & ND & 0.6 & 12.5 & 0.016 \\
\hline M. canis & 2.1 & 0.42 & 0.7 & 7.2 & ND & 1.9 & 2.3 & ND & 0.3 & 6 & 0.004 \\
\hline
\end{tabular}

Table 8. Fungicidal Effects of Species Plant Methanol Extracts Determined

Plant Extract MFC, mg/mL

\begin{tabular}{|c|c|c|c|c|c|c|c|c|c|c|c|}
\hline Dermatophytes & 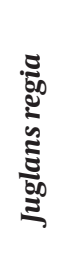 & 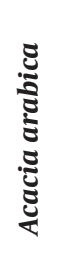 & 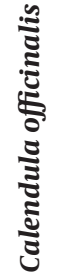 & 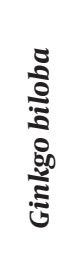 & 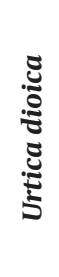 & 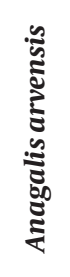 & 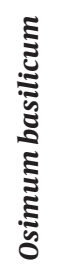 & 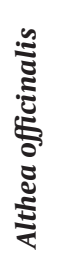 & 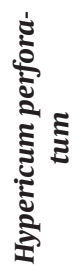 & 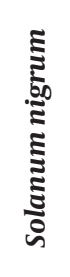 & \\
\hline E. floccosum & 4.4 & 1.6 & 0.8 & 15.25 & ND & 4.40 & 4.6 & ND & 3 & 12.5 & 0.01 \\
\hline T. mentagrophytes & 3.77 & 3.2 & 0.8 & 15.62 & ND & 7.81 & 5.9 & ND & 2.3 & 28 & 0.195 \\
\hline T. schoenleinii & 2.32 & 1.6 & 0.8 & 15.25 & ND & 4.2 & 3.7 & ND & 1.1 & 40 & 0.024 \\
\hline T. rubrum & 3.6 & 3.2 & 1.6 & 15.20 & ND & 3.7 & 3.9 & ND & 1.9 & 28 & 0.048 \\
\hline M. gypseum & 4.2 & 6.4 & 3.2 & 15.62 & ND & 3.7 & 6.8 & ND & 1.5 & 45 & 0.039 \\
\hline M. canis & 3.3 & 6.4 & 6.4 & 15.25 & ND & 4.45 & 6.9 & ND & 1.8 & 12.5 & 0.009 \\
\hline
\end{tabular}

\section{Discussion}

The results of this paper have proved that methanol extract of $H$. perforatum, $A$. arvensis, and A. arabica used in traditional medicine for fungal infections was beneficial. The growth of the strains tested with variable degrees of sensitivity. The extracts of have developed a fungicidal activity with a minimal inhibitory concentration of 0.13 $\mathrm{mg} / \mathrm{mL}$ and $0.17 \mathrm{mg} / \mathrm{mL}$, respectively against $T$. mentagrophytes and T. schoenleinii. The positive results of current study encourage us to the natural molecules responsible for this antifungal activity. The phytochemical analysis revealed the presence of important secondary metabolite (alkaloids, phenolic compounds, saponins, tannins, steroid, flavonoids, and carbohydrates), thus, indicating the therapeutic potentials of extracts. It showed the presence of bioactive compounds as well as the antifungal properties of methanolic extract. The effective use of plant extracts with the lowest MIC and MFC griseofulvin compared with other herbs and extracts from the leaves of plants H. perforatum, A. arabica, and C. officinalis. Among the species tested, the most resistant strain of yeast extract used, M. gypseum most sensitive strains, T. schoenleinii and was E. floccosum. The difference in resistance and susceptibility of strains of extracts used in determining the effective amount of the extract on fungi is important. The results of the study conducted on 22 extracts of medicinal plants in Palestine showed that antifungal activities against on T. mentagrophytes, $M$. canis, and Trichophyton violaceum this is consistent with the results of this study [18].

Another study revealed that Rata chalapensis, J. regia, C. spinusa, and A. arvensis were the most helpful among testing plants (90 - 100\% prohibitive) for dermatophytes [19]. Shoji et al. showed that aqueous and methanol ex- 
tract of A. arvensis contained saponins and flavonoids [20]. The more saponins and carbohydrates are present the higher rate. As the geographical conditions of the amount or type of metabolites are effective on the extraction plants, different regions may have different results. The quantity and quality of the oil and the amount of menthol in different climates can be different in different samples [21]. Thus, it is suggested that plants are maintained under consideration of different sites with different climatic conditions and the effects of climatic conditions amount collected inhibitor compounds examined.

MIC extracts are used in the two types of fungi E. floccosum and T. schoenleinii that inhibited the growth of the fungus by killing them and also a better and faster treatment of infections can be registered because fungicide yeast is helpful. Demonstrating the effectiveness of herbal extracts $H$. perforatum, A. arabica, and C. officinalis listed on fungi, there are hopes that in future the plant assay with purified further investigation, combined with the low side of acceptable and antifungal effects of fungal infection achieved. Effective use of plant extracts with the lowest MIC and MFC griseofulvin compared with other herbs and extracts from the leaves of plants H. perforatum, A. arabica and was C. officinalis. Among the species tested, the most resistant strain of yeast extract used, Araujo et al. using broth microdilution technique, against dermatophytes and MICs for T. mentagrophytes, T. rubrum, and M. canis were ranged from $0.03-1 \mu \mathrm{g} / \mathrm{mL}$ [22].

M. gypseum most sensitive strains than T. schoenleinii and E. floccosum. The difference in resistance and susceptibility of strains of extracts used in determining the effective amount of the extract on fungi is important. MIC extracts used correspond to the two types of fungi E. floccosum and T. schoenleinii that these extracts inhibited the growth of the fungus by killing them and also better and faster treatment of infections due to fungicide yeast is helpful. It is important to investigate plants scientifically so that they can have been used in traditional medicines in order to determine potential sources of novel antimicrobial compounds $[23,24]$. Plants have a long history of antibiotic usage for the cure of disease caused by antimicrobial, including antiviral, antibacterial, and antifungal agents. Antifungal activities of some plants have been reported by various researchers throughout the world like Sharma [25], Giron et al. [26], Mehrabian et al. [27], Farombi [28], Mahesh and Satish [29], Tewarri and Nayak [30], Rajendheran et al. [31], Nair et al. [32], and Prusti et al. [33]. Unfortunately, humans are not the ideal anti-fungal agents.

In addition, the incidence of adverse events and toxicity of fungal resistance phenomenon, most existing antifungal drugs need to be used in the field of power plants to natural antifungal drugs of plant origin may be found to overcome fungal disease. Further studies are needed to determine the antifungal compounds in such plant extract (isolation, separation and identification) as well as its formulation to be applicable as alternative methods to be used in treatment of skin and skin structures diseases in human and animal. Therefore, such results of a significant value that confirms the therapeutic potency of some plants used in traditional medicine. The ultimate conclusion of this study supports the traditional medicine use of different plant extracts in treating different infections caused by pathogenic fungi in Iran either by using a single or combined extracts.

\section{Acknowledgments}

The author appreciates the technical assistance of Dr. Saeid Zarrabi, Biochemistry Department, Faculty of Science, Islamic Azad University of Lahijan, in this research the project number 2414.01 by A. Massiha.

\section{Footnote}

Funding/Support:Islamic Azad University, Lahijan Branch.

\section{References}

1. Sule WF, Okonko IO, Joseph TA, Ojezele MO, Nwanze JC, Alli JA, et al. In vitro antifungal activity of Senna alata Linn. crude leaf extract. Res J Biol Sci. 2010;5(3):275-84.

2. Gangoue-Pieboji J, Pegnyemb DE, Niyitegeka D, Nsangou A Eze N, Minyem C, et al. The in-vitro antimicrobial activities of some medicinal plants from Cameroon. Ann Trop Med Parasitol. 2006;100(3):237-43.

3. Shibata H, Kondo K, Katsuyama R, Kawazoe K, Sato Y, Murakami $\mathrm{K}$, et al. Alkyl gallates, intensifiers of beta-lactam susceptibility in methicillin-resistant Staphylococcus aureus. Antimicrob Agents Chemother. 2005;49(2):549-55.

4. Shiota S, Shimizu M, Sugiyama J, Morita Y, Mizushima T, Tsuchiya T. Mechanisms of action of corilagin and tellimagrandin that remarkably potentiate the activity of beta-lactams against methicillin-resistant Staphylococcus aureus. Microbiol Immunol. 2004;48(1):67-73.

5. Abu-Shanab B, Adwan G, Abu-Safiya D, Jarrar N, Adwan K. Antibacterial activities of some plant extracts utilized in popular medicine in Palestine. Turk J Biol. 2004;28(99):102.

6. Nweze EI. Dermatophytosis in Western Africa: a review. PakJ Biol Sci. 2010;13(13):649-56

7. Monod M. Secreted proteases from dermatophytes. Mycopathologia. 2008;166(5-6):285-94.

8. Ansart S, Perez L, Jaureguiberry S, Danis M, Bricaire F, Caumes E. Spectrum of dermatoses in 165 travelers returning from the tropics with skin diseases. Am J Trop Med Hyg. 2007;76(1):184-6.

9. Hmamouchi M, Tantaoui-Elaraki A, Es-Safi N, Agoumi A. Elucidation of the antibacterial and antifungal properties of the essential oils of Eucalyptus. Plantes Med Phytother.1990;241:278-89.

10. Pattnaik S, Subramanyam VR, Kole C. Antibacterial and antifungal activity of ten essential oils in vitro. Microbios. 1996;86(349):237-46.

11. Nejad BS, Deokule SS. Anti-dermatophytic activity of Drynaria quercifolia (L.) J. Smith. Jundishapur J Microbiol. 2009;2(1):25-30.

12. Yoshida M, Fuchigami M, Nagao T, Okabe H, Matsunaga K, Takata J, et al. Antiproliferative constituents from Umbelliferae plants VII. Active triterpenes and rosmarinic acid from Centella asiatica. Biol Pharm Bull. 2005;28(1):173-5.

13. Soylu EM, Tok FM, Soylu S, Kaya AD, Evrendilek GA. Antifungal activities of essential oils on post harvest disease agent Penicillium digitatum. PakJ Biol Sci. 2005;8:25-9.

14. Iqbal MCM, Meiyalaghan S, Wijesekara KB, Abeyratne KB. Antifungal activity from water extracts of some common weeds. Pak J Biol Sci. 2001;4(7):843-5.

15. Rebell G, Taplin D, Blank H. Dermatophytes: Their recognition and identification.USA: University of Miami Press; 1964 


\section{Massiha A et al.}

16. Shahi SK, Shukla AC, Bajaj AK. Broad spectrum antimitotic drug for the control of fungal infection in human beings. 1998. Available from: http://www.iisc.ernet.in/currsci/mar25/articles29.htm.

17. Clark AM, El-Feraly FS, Li WS. Antimicrobial activity of phenolic constituents of Magnolia grandiflora L. J Pharm Sci. 1981;70(8):951-2.

18. Ali-Shtayeh MS, Abu Ghdeib SI. Antifungal activity of plant extracts against dermatophytes. Mycoses. 1999;42(11-12):665-72.

19. Rothwell JT, Marshall DJ. Suspected poisoning of sheep by Anagallis arvensis (scarlet pimpernel). Aust Vet J. 1986;63(9):316.

20. Shoji N, Umeyama A, Yoshikawa K, Arihara S. Triterpenoid glycosides from Anagallis arvensis. Phytochemistry.1994;37(5):1397-402.

21. Yazdani D, Jamshidi AH, Mojab F. Comparison on menthol content of cultivated Peppermint at different regions of Iran. J Med Plants. 2002;1(3):73-7.

22. Araujo CR, Miranda KC, Fernandes Ode F, Soares AJ, Silva Mdo R. In vitro susceptibility testing of dermatophytes isolated in Goiania, Brazil, against five antifungal agents by broth microdilution method. Rev Inst Med Trop Sao Paulo. 2009;51(1):9-12.

23. Lack HW. Chronological sequence of publications by K. H. Rechinger since 1971. Proceedings of the Royal Society, Sciences. Proceedings of the Royal Society of Edinburgh. Section B. Biolog Sci. ;1986; pp. 3-5.

24. Hammer KA, Carson CF, Riley TV. Antimicrobial activity of essential oils and other plant extracts. J Appl Microbiol.1999;86(6):985-90.

25. Sharma A. Secondary metabolites from tissue cultures of some medicinally important plants. Thesis, University of Rajasthan, Jaipur; 1988.

26. Giron LM, Freire V, Alonzo A, Caceres A. Ethnobotanical survey of the medicinal flora used by the Caribs of Guatemala.J Ethnopharmacol.1991;34(2-3):173-87.

27. Mehrabian S, Molabashi Z. The antimicrobial effect of garlic (Allium sativum) extract on mouth microflora. Iran J Public Health. 1995;24(3-4):39-44.

28. Farombi EO. African indigenous plants with chemotherapeutic potentials and biotechnological approach to the production of bioactive prophylactic agents. Afr J Biotechnol. 2004;2(12):662-71.

29. Mahesh B, Satish S. Antimicrobial activity of some important medicinal plant against plant and human pathogens. World J AGR SCI. 2008;4(5):839-43.

30. Tewari SN, Nayak M. Activity of four plant leaf extracts agaisnt three fungal pathogens of rice. Trop Agr. 1991;68(4):373-5.

31. Rajendhran J, Arun Mani M, Navaneethakannan K. Antibacterial activity of some selected medicinal plants. Geobios. 1998;25(4):280-2.

32. Nair R, Kalariya T, Chanda S. Antibacterial activity of some selected Indian medicinal flora. Turk J Biol. 2005;29(2005):41-7.

33. Prusti A, Mishra SR, Sahoo S, Mishra SK. Antibacterial activity of some Indian medicinal plants. Ethnobot Leaflets . 2008;12:227-30. 